\title{
Ogataea pignaliae sp. nov., the teleomorph of Candida pignaliae
}

\author{
Gábor Péter, Judit Tornai-Lehoczki and Dénes Dlauchy \\ National Collection of Agricultural and Industrial Microorganisms, Faculty of Food Sciences, \\ Corvinus University of Budapest, Hungary
}

Correspondence

Gábor Péter

gabor.peter@uni-corvinus.hu

\begin{abstract}
Six ascosporulating Candida pignaliae strains were isolated from epigeal plant parts in Hungary. They share identical D1/D2 LSU rRNA gene sequences with the type strain of C. pignaliae, and the physiological characteristics investigated are also very similar to that of the type strain. The only substantial difference compared to the type strain of $C$. pignaliae is their ability to assimilate $\beta$-glucosides (cellobiose, salicin and arbutin). The majority of the isolation sources of the strains reported in this study have the common feature of containing tannic acid, while the type strain of C. pignaliae was recovered from tanning fluid. We were able to induce ascosporulation also in the type strain of C. pignaliae. Therefore, Ogataea pignaliae Péter, Tornai-Lehoczki \& Dlauchy sp. nov. is proposed as the teleomorph of C. pignaliae (F. H. Jacob) S. A. Meyer \& Yarrow. The type strain is CBS $6071^{\top}$.
\end{abstract}

Torulopsis pignaliae was described by Jacob (1970) based on six strains isolated from tanning fluid in France and the species was later transferred to the genus Candida by Yarrow \& Meyer (1978). From the six strains mentioned in the original description of $T$. pignaliae, only the type strain was deposited in CBS (Centraalbureau voor Schimmelcultures) and the latest editions of the yeast monographs treated only the type strain of this species (Meyer et al., 1998; Barnett et al., 2000). Jacob (1970) observed copulation but no ascospore formation in the T. pignaliae strains investigated.

In this contribution, we report the isolation of six ascosporulating Candida pignaliae strains. In addition, we were able to induce sporulation also in the type strain of this species. Based on the type strain and the additional sporulating strains, we propose Ogataea pignaliae Péter, Tornai-Lehoczki \& Dlauchy sp. nov. as the teleomorph of Candida pignaliae (Jacob) Meyer \& Yarrow.

The strains considered in this study are shown in Table 1. Tree exudates were sampled with sterile cotton swabs; leaves and mosses were collected with disposable gloves in sterile plastic bags. Yeast strains were isolated by plating on RoseBengal Chloramphenicol (RBC) agar at $25{ }^{\circ} \mathrm{C}$ following a two-step enrichment procedure in Yeast Nitrogen Base (YNB) supplemented with $0.5 \% \quad(\mathrm{v} / \mathrm{v})$ methanol as described by Dlauchy et al. (2003).

Phenotypic characterization of the yeast strains (including the type strain of $C$. pignaliae as a reference) was carried out according to Yarrow (1998). The utilization of carbon sources was examined at $25{ }^{\circ} \mathrm{C}$ on a rotary shaker (30 r.p.m.) for three weeks. Two different products (Sigma G4750, Merck Art. 288) of glucono- $\delta$-lactone were tested as a sole carbon source. The utilization of nitrogen sources was examined by using the conventional auxanographic technique for 7 days. Sporulation was investigated on acetate agar ( $1.4 \%$ sodium acetate, $0.04 \%$ glucose $)$, cornmeal agar, 'spezieller nahrstoffarmer agar' (SNA; $0.1 \% \mathrm{KH}_{2} \mathrm{PO}_{4}, 0.1 \%$ $\mathrm{KNO}_{3}, 0.05 \% \mathrm{MgSO}_{4} .7 \mathrm{H}_{2} \mathrm{O}, 0.05 \% \mathrm{KCl}, 0.02 \%$ glucose, $0.02 \%$ sucrose and $2 \%$ agar), potato dextrose agar, $2 \%$ malt extract agar, glucose-peptone-yeast extract agar, yeast extract-malt extract agar, V8 agar, Gorodkowa agar, modified $\mathrm{KNO}_{3}$ agar $\left[0.14 \% \mathrm{KNO}_{3}, 0.16 \%\right.$ yeast carbon base (Difco), $0.012 \%$ bromothymol blue, $1.6 \%$ agar, $\mathrm{pH}$ : 5.9-6.0] (Pincus et al., 1988) and modified $\mathrm{KNO}_{3}$ agar with double $(0.28 \%) \mathrm{KNO}_{3}$ content at $15{ }^{\circ} \mathrm{C}$ and $25{ }^{\circ} \mathrm{C}$ for 3 weeks.

The D1/D2 domain of the large subunit (26S) rRNA gene from the newly isolated strains was sequenced as described by Kurtzman \& Robnett (1998). The corresponding sequence of C. pignaliae was retrieved from the GenBank database and alignment of the sequences was made with the CLUSTAL X 1.83 program (Thompson et al., 1997).

The six strains reported in this manuscript share identical D1/D2 LSU rRNA gene sequences which are also identical with that of the type strain of $C$. pignaliae, strongly suggesting that they are conspecific (Kurtzman \& Robnett, 1998). The conspecificity of the six new isolates and the type strain of $C$. pignaliae is further substantiated by their phenotypic similarity. However, unlike the type strain of $C$. pignaliae, two strains (NCAIM Y.01825 and NCAIM Y.01826) isolated during this study formed 1-2 hat-shaped ascospores in persistent conjugated or unconjugated asci on V8 agar at $15{ }^{\circ} \mathrm{C}$ after a two- or three-week incubation period, although the sporulation was extremely rare. After a series of unsuccessful attempts not detailed here, finally, we were able to induce sporulation in the remaining strains 
Table 1. List of Ogataea pignaliae sp. nov. strains considered in this study

NCAIM, National Collection of Agricultural and Industrial Micro-organisms, Budapest, Hungary; IFO, Institute for Fermentation, Osaka, Japan; CBS, Centraalbureau voor Schimmelcultures, Utrecht, The Netherlands

\begin{tabular}{|ll|}
\hline Strain accession number & \multicolumn{1}{c|}{ Source of isolation } \\
\hline IFO $10307^{\mathrm{T}}\left(=\mathrm{CBS} 6071^{\mathrm{T}}\right)$ & Tanning fluid, France \\
NCAIM Y.01825 & Exudate of sessile oak (Quercus petrea), Pilis Mountains, Hungary, 2002 \\
NCAIM Y.01826 & Exudate of sessile oak (Quercus petrea), Pilis Mountains, Hungary, 2003 \\
NCAIM Y.01942 & Leaf of agrimony (Agrimonia eupatoria), Pilis Mountains, Hungary, 2006 \\
NCAIM Y.01943 & Leaf of maple (Acer sp.), Pilis Mountains, Hungary, 2006 \\
NCAIM Y.01944, NCAIM Y.01945 & Unidentified moss, Pilis Mountains, Hungary, 2006 \\
\hline
\end{tabular}

as well, including the type strain of $C$. pignaliae. It was recognized that all investigated strains formed ascospores on modified $\mathrm{KNO}_{3}$ agar, at $15{ }^{\circ} \mathrm{C}$ within 3 weeks, although still at low or very low frequency. The modified $\mathrm{KNO}_{3}$ agar was suggested by Pincus et al. (1988) for the quick testing of the potassium nitrate assimilation of clinically important yeasts. We also investigated the performance of modified $\mathrm{KNO}_{3}$ agar with twofold elevated $\mathrm{KNO}_{3}$ content to see if it supported the sporulation, but no significant difference was observed.

Considering their physiological characteristics, the newly isolated strains form a fairly uniform group and differ from the type strain of $C$. pignaliae substantially only by their ability to assimilate three $\beta$-glucosides (cellobiose, salicin and arbutin). A further difference observed compared to the data published by Barnett et al. (2000) is that our isolates assimilated glucono- $\delta$-lactone. However, using two different glucono- $\delta$-lactones from two different suppliers gave invariably positive results for all strains, including the type strain of $C$. pignaliae, indicating that the difference originates in methodology rather than reflecting a real variance.

The type strain of $C$. (Torulopsis) pignaliae was isolated from tanning fluid (Jacob, 1970). Tannic acid is a common phenolic compound, frequently accumulated in various tissues of plants belonging to diverse taxonomic groups (Loureiro et al., 2006). Among the isolation substrates of the novel $O$. pignaliae strains reported in this study (Table 1), oaks and agrimony are known to have high tannic acid contents (Zoldoš et al., 1998; Drozd et al., 1983) and all maple species contain tannins in greater or lesser amounts (Bate-Smith, 1977). Thus, the tannic acid content of at least the majority of the isolation sources of the strains listed in Table 1 indicates that they are tolerant to this compound.

Considering the ability of the type strain of $C$. pignaliae to form ascospores and the additional six conspecific ascosporulating strains, we propose Ogataea pignaliae sp. nov. as the teleomorph of $C$. pignaliae. The phylogenetic position of $O$. pignaliae sp. nov. based on analysis of the D1/D2 large subunit rRNA gene sequences is shown in Fig. 1. When selecting the genus Ogataea to accommodate the teleomorph of $C$. pignaliae, we interpreted the genus Ogataea in a broader sense than Nagatsuka et al. (2008). They even suggested the exclusion of $O$. nitratoaversa, a species which on some phylogenetic trees clusters near to C. pignaliae [see Fig. 1 and Fig. 1 of Nagatsuka et al. (2008)], from the genus. It should also be considered that the genus Pichia is already not available as an alternative taxonomic placement for the teleomorph of C. pignaliae because based on multigene sequence analysis Kurtzman et al. (2008) restricted Pichia to those species that are phylogenetically closely related to Pichia membranifaciens, the type species of the genus. A future multigene sequence analysis may more firmly establish the taxonomic designation of the teleomorph of $C$. pignaliae. Because the number of physiological tests performed in this study exceeds that in the original description of $C$. (Torulopsis) pignaliae (Jacob, 1970), and in addition some characteristics became variable due to the inclusion of additional strains, a detailed description of its teleomorph is given.

\section{Latin diagnosis of Ogataea pignaliae Péter, Tornai-Lehoczki \& Dlauchy, sp. nov.}

Status ascigerus Candida pignaliae (F. H. Jacob) S. A. Meyer \& Yarrow. In extracto malti post dies tres in $25{ }^{\circ} \mathrm{C}$ cellulae sunt globosae vel subglobosae 3-7.5 $\mu \mathrm{m}$, singulae, binae, catenis curtis vel racemis parvis conexae, undique gemmantes. Pellicula non formatur, sedimentum formatur. In agaro malti post dies tres in $25{ }^{\circ} \mathrm{C}$ cultura butyrosa, alba vel cremea, glabra et nitida est. Colonia leviter sublata est, margine integro. In agaro Zea maydis confecto post dies 7 in $25{ }^{\circ} \mathrm{C}$ nec pseudohyphae nec hyphae formantur. Asci conjugati vel inconjugati, (1)-2 ascosporas petasoformes, non liberas habent. Species est homothallica. D-Glucosum et trehalosum (fortasse lente) fermentantur. D-Galactosum, maltosum, sucrosum, lactosum, raffinosum non fermentantur. D-Glucosum, L-sorbosum (fortasse lente), D-ribosum (fortasse lente), D-xylosum, L-arabinosum, trehalosum, cellobiosum (variabile), salicinum (variabile), arbutinum (variabile), glycerolum, meso-erythritolum (exigue, lente, variabile), ribitolum, xylitolum, L-arabinitolum, D-glucitolum, D-mannitolum, glucono- $\delta$-lactonum, D-gluconicum (lente, variabile), succinatum, methanolum, ethanolum, propane-1,2-diolum (fortasse lente) assimilantur, at non 


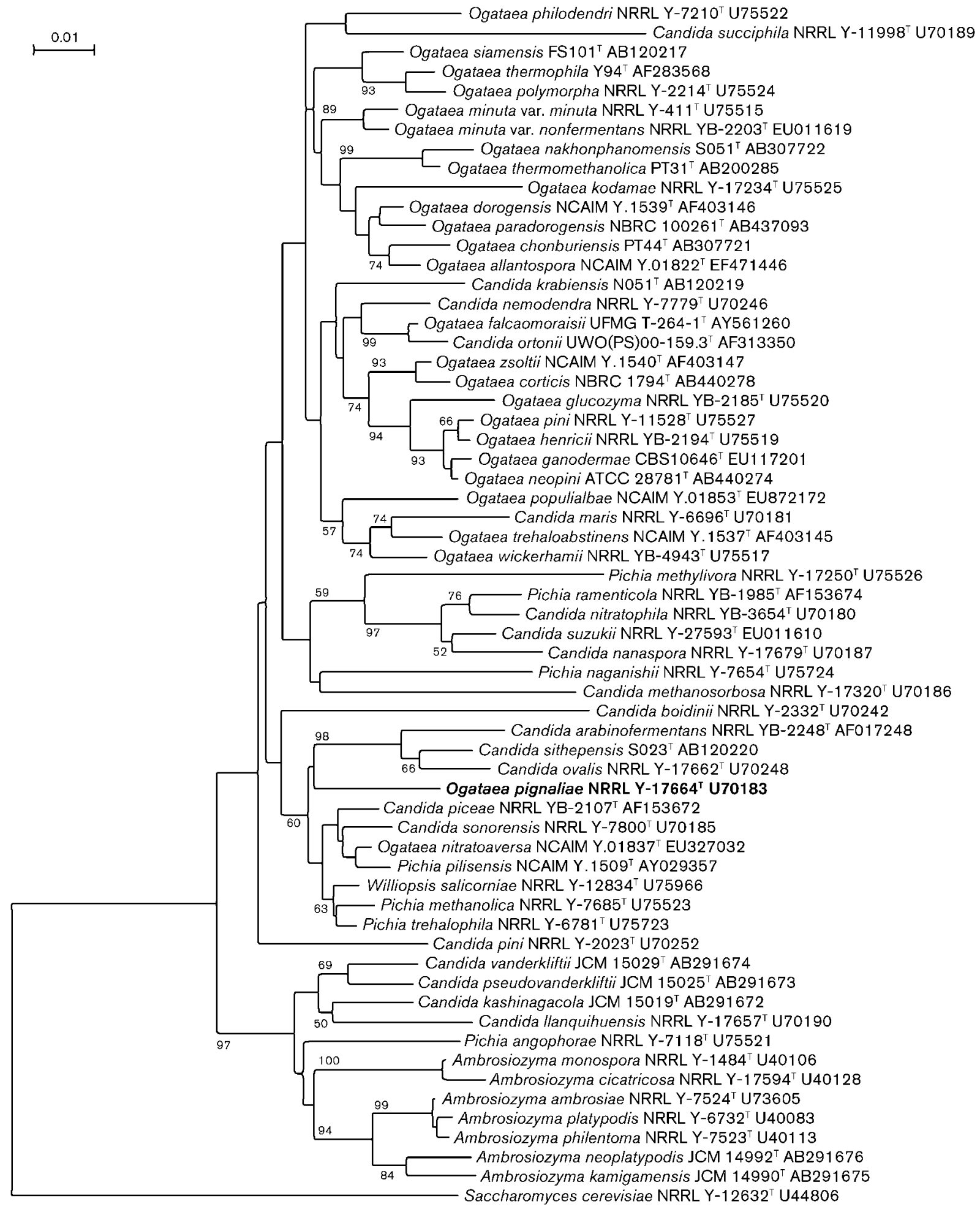

Fig. 1. Phylogenetic tree showing the placement of Ogataea pignaliae sp. nov. (bold) and some related species based on analysis of the D1/D2 domain of the large subunit rRNA gene. Sequences were obtained from GenBank. The tree was reconstructed by neighbour-joining analysis of aligned sequences. Numbers at branches indicate the bootstrap values from 1000 replications (frequencies of less than $50 \%$ are not shown). Bar, proportional sequence divergence. 
D-galactosum, D-glucosaminum, $N$-acetyl-D-glucosaminum, Darabinosum, L-rhamnosum, sucrosum, maltosum, methyl $\alpha$-Dglucosidum, melibiosum, lactosum, raffinosum, melezitosum, inulinum, amylum solubile, galactitolum, myo-inositolum, 2-ketogluconicum, D-glucuronicum, D-galacturonicum, DLlactatum, citratum, butane-2,3-diolum, hexadecanum et saccharatum. Kalium nitricum, natrium nitrosum, ethylaminum hydrochloricum, lysinum et cadaverinum dihydrochloricum assimilantur, at non creatinum, creatininum, glucosaminum, imidazolum. Materia amyloidea iodophila non formatur. Vitamina externa crescentiae sunt necessaria. Crescere potest in $30{ }^{\circ} \mathrm{C}$, at non in $35{ }^{\circ} \mathrm{C}$. Non crescit in agaro extracto fermenti confecto 50 partes glucosi per centum. Parte una cycloheximidi per mille crescit. Ureum non finditur. Diazonium caeruleum B est negativum. Typus stirps CBS $6071^{\mathrm{T}}$. Isolata ex liquore coriario, Gallia.

\section{Description of Ogataea pignaliae Péter, Tornai- Lehoczki \& Dlauchy sp. nov.}

Ogataea pignaliae (pig.nal.i'ae. N.L. gen. fem. sing. n. pignaliae of Pignal, named after F. Pignal, and also to indicate that this species is the teleomorph pair of Candida pignaliae).

Anamorph: Candida pignaliae (F. H. Jacob) S. A. Meyer \& Yarrow. [Yarrow \& Meyer, Int J Syst Evol Bacteriol 28 (1978), 611-615].

In $5 \%$ malt extract after 3 days at $25{ }^{\circ} \mathrm{C}$, cells are globose or subglobose and $3-7.5 \mu \mathrm{m}$. Cell division proceeds by multilateral budding. Cells occur singly, in pairs, in short chains and in small clusters. Pellicle is absent; a compact sediment is present. On $5 \%$ malt extract agar after 3 days at $25{ }^{\circ} \mathrm{C}$, the streak culture is butyrous, slightly raised, white to cream-coloured, smooth and glistening. The margin is entire. On cornmeal agar after 10 days at $25{ }^{\circ} \mathrm{C}$, neither pseudohyphae nor septate hyphae are formed. Asci are either unconjugated, or conjugation of independent cells or parent cell-bud conjugation precedes ascospore formation. One (rarely) or two hat-shaped ascospores are formed in each ascus (Fig. 2). The great majority of the asci are persistent. The presence of asci showing heterogamous conjugation suggests that the species is homothallic. Sporulation is observed in all strains on modified $\mathrm{KNO}_{3}$ agar or on modified $\mathrm{KNO}_{3}$ agar with double $\mathrm{KNO}_{3}$ content within three weeks at $15{ }^{\circ} \mathrm{C}$. D-Glucose and $\alpha, \alpha$-trehalose (positive or slow) are fermented; D-galactose, maltose, sucrose, lactose and raffinose are not fermented. Carbon compounds D-glucose, L-sorbose (positive or slow), Dribose (positive or slow), D-xylose, L-arabinose, $\alpha, \alpha$ trehalose, cellobiose (variable), salicin (variable), arbutin (variable), glycerol, meso-erythritol (weak, slow and variable), ribitol, xylitol, L-arabinitol, D-glucitol, D-mannitol, glucono- $\delta$-lactone, D-gluconate (slow and variable), succinate, methanol, ethanol and propane-1,2-diol (positive or slow) are assimilated; no growth occurs on Dgalactose, D-glucosamine, $\mathrm{N}$-acetyl-D-glucosamine, D-arabinose, L-rhamnose, sucrose, maltose, methyl $\alpha$-D-glucoside,

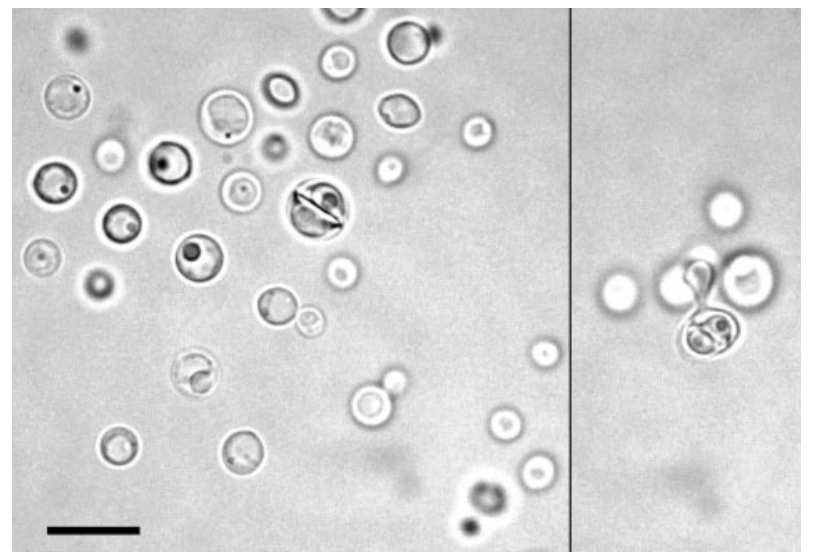

Fig. 2. Ascosporulating cultures of Ogataea pignaliae sp. nov. CBS $6071^{\top}$ (modified $\mathrm{KNO}_{3}$ agar with double $\mathrm{KNO}_{3}$ content, 21 days, $\left.15^{\circ} \mathrm{C}\right)$. Bar, $10 \mu \mathrm{m}$.

melibiose, lactose, raffinose, melezitose, inulin, starch, galactitol, myo-inositol, 2-keto-D-gluconate, D-glucuronate, D-galacturonate, DL-lactate, citrate, butane-2,3-diol, hexadecane or saccharate. Potassium nitrate, sodium nitrite, ethylamine hydrochloride, L-lysine and cadaverine dihydrochloride are assimilated; creatine, creatinine, glucosamine (as nitrogen source) and imidazole are not assimilated. The formation of amyloid material is negative. Growth in vitamin-free medium is negative. Growth occurs at $30{ }^{\circ} \mathrm{C}$ and is negative at $35{ }^{\circ} \mathrm{C}$. No growth occurs on $50 \%(\mathrm{w} / \mathrm{w})$ glucose yeast extract agar and with $10 \% \mathrm{NaCl}$ or with $1 \%$ acetic acid. Growth with $0.1 \%$ cycloheximide is positive. Urea hydrolysis, and colour reaction with Diazonium blue B are negative.

The type strain was recovered from tanning fluid (Jacob, 1970) in France and is maintained as CBS $6071^{\mathrm{T}}$ in Centraalbureau voor Schimmelcultures, Utrecht, The Netherlands.

\section{References}

Barnett, J. A., Payne, R. W. \& Yarrow, D. (2000). Yeasts: Characteristics and Identification, 3rd edn. Cambridge: Cambridge University Press.

Bate-Smith, E. C. (1977). Astringent tannins of Acer species. Phytochemistry 16, 1421-1426.

Dlauchy, D., Tornai-Lehoczki, J., Fülöp, L. \& Péter, G. (2003). Pichia (Komagataella) pseudopastoris sp. nov., a new yeast species from Hungary. Antonie van Leeuwenhoek 83, 327-332.

Drozd, G. A., Yavlyanskaya, S. F. \& Inozemtseva, T. M. (1983). Phytochemical investigation of Agrimonia eupatoria. Chem Nat Compd 19, 104.

Jacob, F. (1970). Deux espèces nouvelles de levures asporogènes isolées de liqueurs tannantes végétales. Ann Inst Pasteur (Paris) 118, 207-213.

Kurtzman, C. P. \& Robnett, C. J. (1998). Identification and phylogeny of ascomycetous yeasts from analysis of nuclear large subunit (26S) 
ribosomal DNA partial sequences. Antonie van Leeuwenhoek 73, 331371.

Kurtzman, C. P., Robnett, C. J. \& Basehoar-Powers, E. (2008). Phylogenetic relationships among species of Pichia, Issatchenkia and Williopsis determined from multigene sequence analysis, and the proposal of Barnettozyma gen. nov., Lindnera gen. nov. and Wickerhamomyces gen. nov. FEMS Yeast Res 8, 939-954.

Loureiro, J., Rodriguez, E., Dolezel, J. \& Santos, C. (2006). Flow cytometric and microscopic analysis of the effect of tannic acid on plant nuclei and estimation of DNA content. Ann Bot 98, 515-527.

Meyer, S. A., Payne, R. W. \& Yarrow, D. (1998). Candida Berkhout. In The Yeasts: a Taxonomic Study, 4th edn, pp. 454-573. Edited by C. P. Kurtzman \& J. W. Fell. Amsterdam: Elsevier.

Nagatsuka, Y., Saito, S. \& Sugiyama, J. (2008). Ogataea neopini sp. nov. and $O$. corticis sp. nov., with the emendation of the ascomycete yeast genus Ogataea, and transfer of Pichia zsoltii, $P$. dorogensis, and $P$. trehaloabstinens to it. J Gen Appl Microbiol 54, 353-365.
Pincus, D. H., Salkin, I. F., Hurd, N. J., Levy, I. L. \& Kemna, M. A. (1988). Modification of potassium nitrate assimilation test for identification of clinically important yeasts. J Clin Microbiol 26, 366-368.

Thompson, J. D., Gibson, T. J., Plewniak, F., Jeanmougin, F. \& Higgins, D. G. (1997). The CLUSTAL_X windows interface: flexible strategies for multiple sequence alignment aided by quality analysis tools. Nucleic Acids Res 25, 4876-4882.

Yarrow, D. (1998). Methods for the isolation, maintenance and identification of yeasts. In The Yeasts, a Taxonomic Study, 4th edn, pp. 77-100. Edited by C. P. Kurtzman \& J. W. Fell. Amsterdam: Elsevier.

Yarrow, D. \& Meyer, S. A. (1978). Proposal for amendment of the diagnosis of the genus Candida Berkhout nom. cons. Int J Syst Bacteriol 28, 611-615.

Zoldoš, V., Papeš, D., Brown, S. C., Panaud, O. \& Šiljak-Yakovlev, S. (1998). Genome size and base composition of seven Quercus species: inter- and intra-population variation. Genome 41, 162-168. 